\title{
Lithium ion conducting PVdF-HFP composite gel electrolytes based on $N$-methoxyethyl- $N$-methylpyrrolidinium bis(trifluoromethanesulfonyl)-imide ionic liquid
}

\author{
S. Ferrari ${ }^{a}$, E. Quartarone ${ }^{\mathrm{a}, *}$, P. Mustarelli $^{\mathrm{a}}$, A. Magistris $^{\mathrm{a}}$, M. Fagnoni $^{\mathrm{b}}$, \\ S. Protti ${ }^{\mathrm{b}}$, C. Gerbaldi ${ }^{\mathrm{c}}$, A. Spinella ${ }^{\mathrm{d}}$ \\ a Dept. of Physical Chemistry, University of Pavia, Via Taramelli 16, 27100 Pavia, Italy \\ b Dept. of Organic Chemistry, University of Pavia, Via Taramelli 12, 27100 Pavia, Italy \\ ${ }^{\mathrm{c}}$ Dept. of Material Science and Chemical Engineering, Politecnico di Torino, C.so Duca degli Abruzzi, 24, 10129 Torino, Italy \\ d Centro Grandi Apparecchiature - UniNetLab, University of Palermo, Via F. Marini 14, 90128 Palermo, Italy
}

\section{A R T I C L E I N F O}

\section{Article history:}

Received 18 May 2009

Accepted 8 August 2009

Available online 15 August 2009

\section{Keywords:}

PVdF

Ionic liquids

Pyrrolidinium

Gel polymer electrolytes

Lithium battery

Nanoscale fillers

\begin{abstract}
A B S T R A C T
Blends of PVdF-HFP and ionic liquids (ILs) are interesting for application as electrolytes in plastic Li batteries. They combine the advantages of the gel polymer electrolytes (GPEs) swollen by conventional organic liquid electrolytes with the nonflammability, and high thermal and electrochemical stability of ILs.

In this work we prepared and characterized PVdF-HFP composite membranes swollen with a solution of LiTFSI in ether-functionalized pyrrolidinium-imide ionic liquid (PYRA ${ }_{1201}$ TFSI). The membranes were filled in with two different types of silica: (i) mesoporous $\mathrm{SiO}_{2}$ (SBA-15) and (ii) a commercial nano-size one (HiSil $\left.{ }^{\mathrm{TM}} \mathrm{T700}\right)$. The ionic conductivity and the electrochemical properties of the gel electrolytes were studied in terms of the nature of the filler.

The thermal and the transport properties of the composite membranes are similar. In particular, room temperature ionic conductivities higher than $0.25 \mathrm{mS} \mathrm{cm}^{-1}$ are easily obtained at defined filler contents. However, the mesoporous filler guarantees higher lithium transference numbers, a more stable electrochemical interface and better cycling performances. Contrary to the HiSil ${ }^{\mathrm{TM}}$-based membrane, the $\mathrm{Li} / \mathrm{LiFePO}_{4}$ cells with PVdF-HFP/PYRA 1201 TFSI-LiTFSI films containing $10 \mathrm{wt} \%$ of SBA-15 show good charge/discharge capacity, columbic efficiency close to unity, and low capacity losses at medium C-rates during 180 cycles.
\end{abstract}

() 2009 Elsevier B.V. All rights reserved.

\section{Introduction}

The research in the field of lithium batteries is now focused on the development of safer and more thermally stable electrolytes [1]. The flammability and volatility of the conventional liquid electrolytes, in fact, still remains a critical point. Room temperature ionic liquids (RTIL) seem to be a promising alternative to the organic carbonates as solvents for lithium batteries, because they are nonflammable, nonvolatile and liquid in a wide range of temperatures. Among the several cations studied during the last ten years, the pyrrolidinium-based ones show the best properties in terms of conductivity and electrochemical window [2-5]. Recently, we synthesized and characterized an ether-functionalized pyrrolidinium-imide ionic liquid, in which different amounts of LiTFSI were dissolved in order to test it as an

\footnotetext{
* Corresponding author. Tel.: +39 0382 987894; fax: +39 0382987776 .

E-mail address: eliana.quartarone@unipv.it (E. Quartarone).
}

electrolyte for lithium batteries [6]. We showed that the presence of oxygen atoms in the lateral chain of the cation gives higher conductivity and lower viscosity than standards pyrrolidinium-based ILs, particularly for salt concentration around $0.41 \mathrm{~mol} \mathrm{~kg}^{-1}$.

Some attempts were also made to disperse the ionic liquids in polymer electrolytes to prepare plastic lithium ion batteries with better performances [7-10]. The advantage of the gel electrolytes is well known: they chiefly combine good electrochemical properties with the capability of large liquid uptakes, without losing the free-standing features of certain polymer materials [11]. Due to the wide variety of polymers available in the market, a great number of GPEs was described in the literature, generally based on polymethylmethacrilate (PMMA), polyacrylonitrile (PAN), polyethylene oxide (PEO) and, mostly, homo- and copolymer of polyvinilidenefluoride (PVdF) [11]. However, the gel electrolytes still suffer from a lack of stability with time, both because of the leaching of liquid from the membrane, and also because of chemical and electrochemical reactions at the electrode/electrolyte interfaces. 
The positive effects of inorganic fillers on the properties of polymer electrolytes were reported in the literature [12]. Many types of ceramic and glassy oxides, like $\mathrm{TiO}_{2}, \mathrm{Al}_{2} \mathrm{O}_{3}, \mathrm{SiO}_{2}, \mathrm{MgO}, \gamma \mathrm{LiAlO}_{2}$ were dispersed in several polymers, by varying the filler concentration, microstructure and particle sizes [13-16], and in such cases also by properly functionalizing the filler surface $[17,18]$. This number of studies demonstrated that, in general, the filler does not remarkably affect the gel conductivity, which is high enough for potential applications, rather it improves the interfacial properties and the lithium transference number of the membranes, as well as the liquid retention capability and the membrane dimensional strength. Particular attention was recently devoted to the use of $\mathrm{SiO}_{2}$ nanosize particles with very high surface area, and mesoporous silicas, like SBA-15 and MCM-41, which allow an extended polymer/filler interphase [19-22].

In this study we prepare PVdF-HFP based gel electrolytes, swollen in a weight ratio $30: 70$ by a $0.41 \mathrm{~mol} \mathrm{~kg}^{-1}$ solution of LiTFSI in PYRA P $_{1201}$ TFSI. Two types of silica fillers were dispersed in the gels, a commercial nano-size $\mathrm{SiO}_{2}\left(\mathrm{HiSil}^{\mathrm{TM}} \mathrm{T} 700\right)$ and a hierarchical one (SBA-15), in order to discuss the role of the filler microstructure on the conductivity and on the electrochemical properties of the polymer electrolytes. Each membrane was thoroughly characterized from the physico-chemical and electrochemical points of view. Battery tests, performed at room temperature on the solid-state cell $\mathrm{Li} /$ composite gel polymer/LiFePO 4 , are also presented.

\section{Experimental details}

\subsection{Synthesis of PYRA $A_{1201}$ TFSI and preparation of the PYRA 1201 TFSI-LiTFSI solution}

The ionic liquid PYRA 1201 TFSI (see Scheme 1) was synthesized as reported elsewhere [6]. A lithium salt-ionic liquid solution of molality $0.41 \mathrm{~mol} \mathrm{~kg}^{-1}$ was prepared by adding a proper amount of LiTFSI, previously dissolved in acetone, to the purified ionic liquid. The solution was dried at $70^{\circ} \mathrm{C}$ in order to completely remove the solvent. Each operation was carried out in a dry-box (MBraun, $\mathrm{O}_{2}<1 \mathrm{ppm}, \mathrm{H}_{2} \mathrm{O}<1 \mathrm{ppm}$ ) under argon atmosphere.

\subsection{Preparation of PVdF-HFP nanocomposite gels}

PVdF ( 5 mol\% HFP) was obtained by Solvay. The 30 wt\% PVdFHFP-70 wt\% PYRA 1201 TFSI-LiTFSI nanocomposite gel electrolytes were prepared by the conventional casting technique using acetone as the solvent. Different amounts of filler, ranging from 5 to $20 \mathrm{wt} \%$ (with respect to the polymer) were dispersed in the solutions. All the procedures were carried out in the dry-box.

Two different types of silica, namely SBA-15 and HiSil ${ }^{\mathrm{TM}} \mathrm{T} 700$ were used as the filler. SBA-15 was synthesised as reported elsewhere [23]. As already stated, SBA-15 has a well ordered hexagonal mesoporous structure with a very narrow pore sizes distribution peaked at $6 \mathrm{~nm}$. Its pore specific volume and surface area are $1.5 \mathrm{~cm}^{3} \mathrm{~g}^{-1}$ and $1150 \mathrm{~m}^{2} \mathrm{~g}^{-1}$, respectively. HiSil ${ }^{\mathrm{TM}} \mathrm{T} 700$ is a commercial nano-size silica (Degussa) with a pore size distribution around $20 \mathrm{~nm}$, a surface area not higher than $240 \mathrm{~m}^{2} \mathrm{~g}^{-1}$ and a

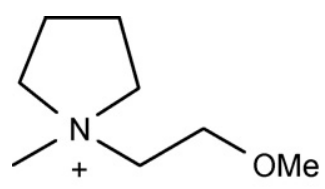

TFSI $^{-}$

Scheme 1. Chemical structure of $N$-ethyl(methylether)- $N$-methylpyrrolidinium trifluoromethanesulfonimmide (PYRA1201). pore specific volume of $0.4 \mathrm{~cm}^{3} \mathrm{~g}^{-1}$. $\mathrm{HiSil}^{\mathrm{TM}} \mathrm{T} 700$ also contains $8-10$ hydroxyl groups per $\mathrm{nm}^{2}$ of surface.

\section{3. $\mathrm{LiFePO}_{4}$ cathode preparation and cell assembly}

High surface area nanostructured $\mathrm{LiFePO}_{4} / \mathrm{C}$ was obtained by hydrothermal synthesis in the presence of an organic surfactant, as reported in a previous work [24]. The $\mathrm{LiFePO}_{4} / \mathrm{C}$ composite electrode was prepared by spreading a slurry of the active material on an $\mathrm{Al}$ current collector by means of a doctor blade. The slurry is composed by the olivine ( $82 \mathrm{wt} \%$, typically $\sim 3 \mathrm{mg} \mathrm{cm}^{-2}$ ), acetylene black (10wt\%, Shawinigan Black AB50, Chevron Corp., USA) and poly(vinylidene fluoride) ( $8 \mathrm{wt} \%$, PVdF, Solvay Solef 6020), dispersed in $\mathrm{N}$-methyl-2-pyrrolidone (NMP, Aldrich). After the evaporation of the solvent, disks of $0.785 \mathrm{~cm}^{2}$ were punched out of the foil and dried by heating at $130^{\circ} \mathrm{C}$ under high vacuum for $\sim 5 \mathrm{~h}$.

The lithium polymer cell was assembled by contacting in sequence a lithium metal (Aldrich) disk anode, the gel composite electrolyte and a disk of the composite cathode. The electrodes/electrolyte assembly was housed in a Teflon-made Swagelok cell (area $0.785 \mathrm{~cm}^{2}$ ), equipped with two stainless-steel SS-316 current collector electrodes. Both electrode fabrication and cell assembly were performed in an environmentally controlled Ar-filled dry-box.

\subsection{Instrumentation}

DSC measurements were performed with a 2910 MDSC (TA Instruments) by using aluminium pans, at a rate of $5^{\circ} \mathrm{C} \mathrm{min}^{-1}$ under nitrogen purge. TGA scans were recorded at $10^{\circ} \mathrm{Cmin}^{-1}$ under nitrogen flow with a 2950 TGA (TA Instruments).

${ }^{13} \mathrm{C}\left\{{ }^{1} \mathrm{H}\right\}$ CP-MAS NMR spectra were obtained at room temperature using a Bruker Avance II $400 \mathrm{MHz}$ (9.4T) spectrometer operating at $100.63 \mathrm{MHz}$ for the ${ }^{13} \mathrm{C}$ nucleus. A MAS rate of $13 \mathrm{kHz}$ was chosen to remove the spinning sidebands. A $90^{\circ}$ pulse on the ${ }^{1} \mathrm{H}$ nucleus of $3.65 \mu$ s was used. The contact time of $1.5 \mathrm{~ms}$ was optimized with variable contact time experiments. A repetition delay optimized to $2 \mathrm{~s}$, an acquisition time of $34 \mathrm{~ms}$ and 1500 scans were employed. The optimization of the Hartmann-Hahn condition was obtained with an adamantane sample standard.

Impedance spectroscopy sweeps were carried out to measure the gel ionic conductivity, by using a frequency response analyser (FRA Solartron 1255), connected to an electrochemical interface (Solartron 1287), over the frequency range $1 \mathrm{~Hz}-1 \mathrm{MHz}$ at a voltage of $100 \mathrm{mV}$. The impedance scans were performed onto a two SS electrodes cell (cell constant $2 \mathrm{~cm}^{-1}$ ) in the temperature range between -25 and $60^{\circ} \mathrm{C}$. The stability of the polymer electrolytes against lithium was investigated by monitoring the time evolution of the impedance on a symmetric $\mathrm{Li} /$ electrolyte/Li cell.

Linear and cyclic voltammetry were performed with a three electrodes cell, in which lithium was both the counter and the reference electrode, and nickel the working one. In the case of liquid electrolyte, the three electrode cell (Cypress Systems) was made of glassy carbon as the working electrode, a Pt wire as the counter one and $\mathrm{Ag} / \mathrm{Ag}^{+}\left(\mathrm{CH}_{3} \mathrm{CN}, 1 \mathrm{mM} \mathrm{AgNO}{ }_{3}\right)$ as the reference. The effective electrode area of the glassy carbon electrode, $0.033 \mathrm{~cm}^{2}$, was calculated from cyclic voltammograms on a $1 \mathrm{mM}$ ferrocene solution in $\mathrm{CH}_{3} \mathrm{CN}$ ( $0.1 \mathrm{M}$ tetrabutylammonium perclorate), by applying the Randles-Sevcik equation to the resulting peak current:

$i_{p}=0.4463 n F(n F / R T)^{1 / 2} A D^{1 / 2} v^{1 / 2} c$

where $i_{p}$ is the peak current, $n$ is the number of electrons in the charge transfer step, $A$ is the electrode area, $D$ is the diffusion coef- 
ficient of $F c\left(2.5 \times 10^{-5} \mathrm{~cm}^{2} \mathrm{~s}^{-1}\right), c$ is the concentration and $v$ is the scan rate $\left(10 \mathrm{mV} \mathrm{s}^{-1}\right)$.

The lithium transference number, $T_{\mathrm{Li}}{ }^{+}$, was determined by a dc polarization combined with impedance spectroscopy, as proposed by Bruce and Evans $[25,26]$. The method consists in applying a small dc pulse, $\Delta V$, to a symmetrical Li/electrolyte/Li cell and measuring the initial, $I_{0}$, and the steady-state, $I_{\mathrm{ss}}$, currents which flow through the cell. The same cell was also monitored by impedance spectroscopy to detect the initial, $R_{0}$, and the final, $R_{\mathrm{Ss}}$, resistances of the two Li interfaces in order to account for the resistance of passivation layers and the eventual increase of this value upon the duration of the dc pulse. Under these circumstances, the lithium transference number, $T_{\mathrm{Li}}{ }^{+}$, is given by:

$T_{\mathrm{Li}}{ }^{+}=\frac{I_{\mathrm{ss}}}{I_{0}} \frac{\Delta V-I_{0} R_{0}}{\Delta V-I_{\mathrm{SS}} R_{\mathrm{SS}}}$

The $\mathrm{Li} / \mathrm{LiFePO}_{4}$ cells were tested at room temperature in terms of charge/discharge galvanostatic cycling (cut-off voltages to $2.50-4.00 \mathrm{~V} \mathrm{vs}$. $\mathrm{Li}^{+} / \mathrm{Li}$, starting from O.C.V.) at different current regimes using an Arbin Instrument Testing System model BT-2000.

\section{Results and discussion}

\subsection{The ionic liquid electrolyte}

As already described in Section 2, the PVdF-HFP based membranes were swollen with an ionic liquid electrolyte made of a solution of LiTFSI in PYRA 1201 TFSI. In our previous paper [6], we showed that the addition of LiTFSI up to concentrations of $0.41 \mathrm{~mol} \mathrm{~kg}^{-1}$ does not change substantially the viscosity of the pure ionic liquid. Conductivity values exceeding $1 \mathrm{mS} \mathrm{cm}^{-1}$ were obtained at $20^{\circ} \mathrm{C}$ with no dramatic losses at sub-ambient temperatures.

Fig. 1 reports the linear voltammetry of the PYRA $A_{1201}$ TFSI-salt system (curve a) and of the pure ionic liquid (curve b). The electrochemical data were obtained using an $\mathrm{Ag}^{+} / \mathrm{Ag}$ reference electrode calibrated to the ferrocene-ferrocinium redox couple in order to obtain an absolute reference. By comparing the two plots, we see that the solution is electrochemically more stable than the pure ionic liquid. Its stability window is $5.8 \mathrm{~V}$, ranging from -3.3 to $2.5 \mathrm{~V}$ vs. $\mathrm{Fc} / \mathrm{Fc}^{+}$, whereas PYRA 1201 TFSI has a significantly smaller window of $4.9 \mathrm{~V}$ (from -2.2 to $2.7 \mathrm{vs}$. $\mathrm{Fc} / \mathrm{Fc}^{+}$). The difference in the reduction stability ( $-3.3 \mathrm{~V}$ for the solution and $-2.2 \mathrm{~V}$ for the liquid) is probably related to the presence of a higher amount of the TFSI ${ }^{-}$ anion coming from the dissolved salt. It is known from the literature

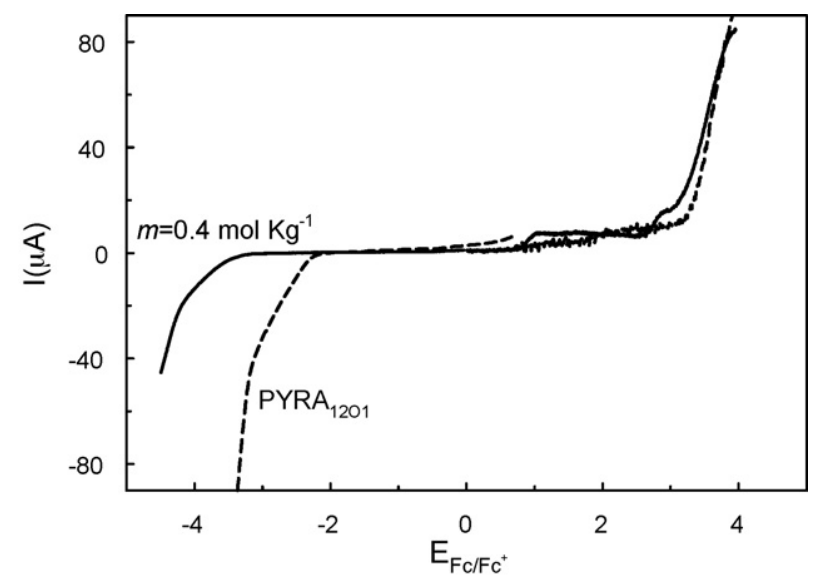

Fig. 1. Sweeps of linear voltammetry of the $P Y R A_{1201}$ TFSI ionic liquid (dashed line) and of the PYRA 1201 TFSI-LiTFSI solution $\left(m=0.41 \mathrm{~mol} \mathrm{~kg}^{-1}\right)$ (solid line) vs. Fc/Fc'. Scan rate: $10 \mathrm{mV} \mathrm{s}^{-1}$.

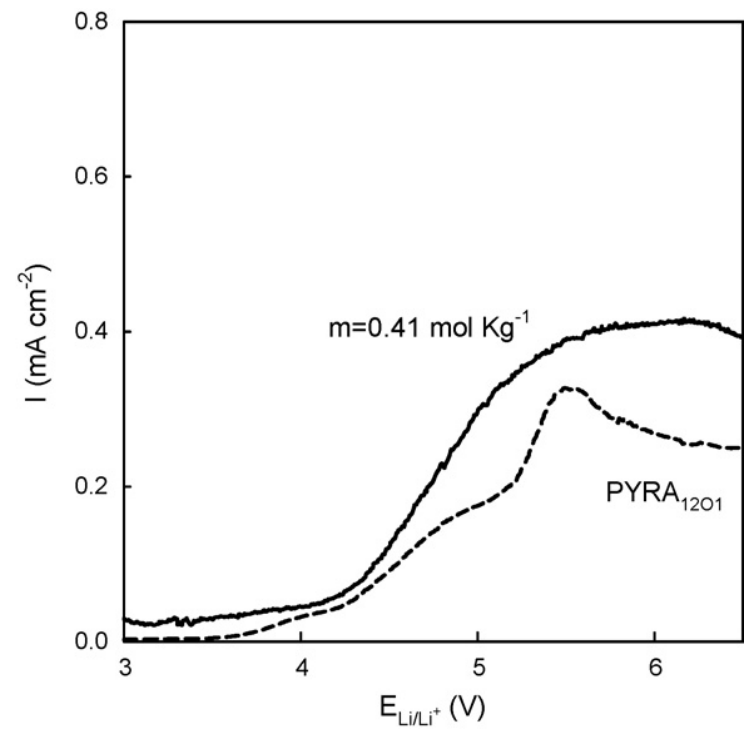

Fig. 2. Sweeps of linear voltammetry of the PYRA 1201 TFSI ionic liquid (dashed line) and of the PYRA 1201 TFSI-LiTFSI solution $\left(m=0.41 \mathrm{~mol} \mathrm{~kg}^{-1}\right)$ (solid line) vs. Li/ $\mathrm{Li}^{+}$. Scan rate: $10 \mathrm{mV} \mathrm{s}^{-1}$.

that the reduction limit of this kind of anion in pyrrolidiniumbased structures causes decomposition processes, leading to the formation of a protective passivation layer on the working electrode which somehow prevents the reduction of the cation [27].

Fig. 2 compares the curves of the linear voltammetry sweeps vs. $\mathrm{Li} / \mathrm{Li}^{+}$for the salt-doped ionic liquid and the pure one. In this case no remarkable differences could be noted in the oxidation currents when LiTFSI is present, and similar electrochemical windows around $4 \mathrm{~V}$ vs. $\mathrm{Li} / \mathrm{Li}^{+}$were observed for both the samples.

\subsection{The PVdF-HFP gel composite electrolytes}

\subsubsection{Membrane-electrolyte-filler interactions}

Fig. 3 shows the ${ }^{13} \mathrm{C}\left\{{ }^{1} \mathrm{H}\right\}$ CP-MAS NMR spectra of the electrolyte membrane, and of the electrolyte membrane with 5 wt\% of SBA- 15 . The two peaks at $\sim 43.0$ and $\sim 120 \mathrm{ppm}$ represent the resonances

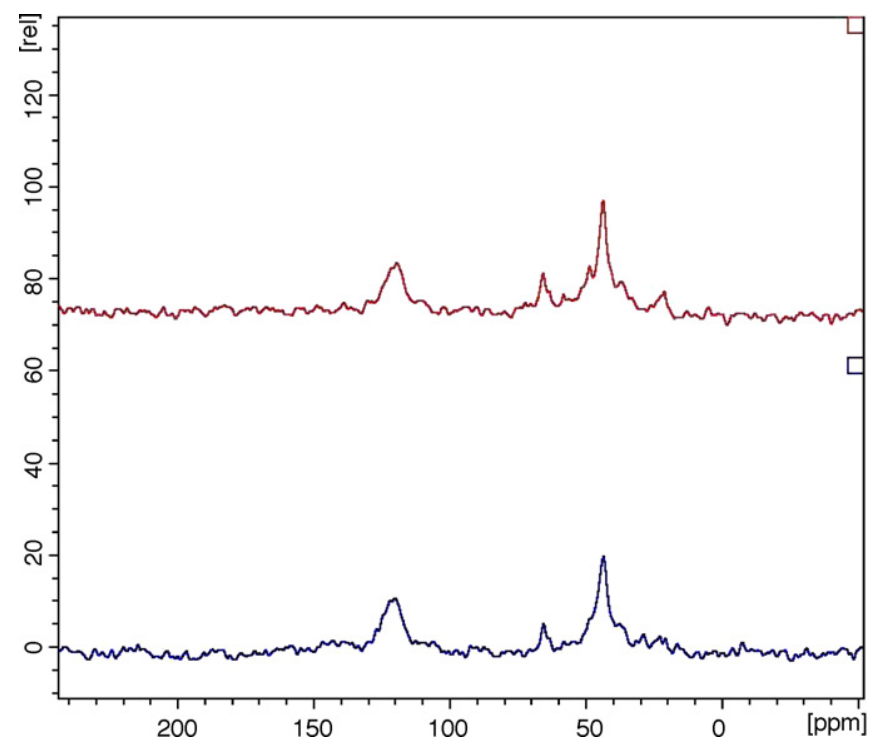

Fig. 3. ${ }^{13} \mathrm{C}\left\{{ }^{1} \mathrm{H}\right\}$ CP-MAS NMR spectra of the polymer electrolyte (blue) and the polymer electrolyte with $5 \mathrm{wt} \%$ of SBA-15 (red). (For interpretation of the references to colour in this figure legend, the reader is referred to the web version of the article.) 
Table 1

Thermal, transport and electrochemical properties of the PVdF-based gel composite electrolytes.

\begin{tabular}{|c|c|c|c|c|c|c|c|c|}
\hline PVdF-HFP/PYRA 1201 TFSI-LiTFSI (30-70 wt\%) & $T_{g}(\mathrm{~K})$ & $\sigma_{-20^{\circ} \mathrm{C}}\left(\mathrm{mS} \mathrm{cm}^{-1}\right)$ & $\sigma_{20^{\circ} \mathrm{C}}\left(\mathrm{mS} \mathrm{cm}^{-1}\right)$ & $\sigma_{60^{\circ} \mathrm{C}}\left(\mathrm{mS} \mathrm{cm}^{-1}\right)$ & $\mathrm{T}_{\mathrm{Li}}{ }^{+} 20^{\circ} \mathrm{C}$ & $\mathrm{E} . \mathrm{W}_{\cdot \mathrm{Li} / \mathrm{Li}}{ }^{+}(\mathrm{V})$ & $E_{a}(\mathrm{eV})$ & $T_{0}(\mathrm{~K})$ \\
\hline 0 & $183 \pm 2$ & 0.012 & 0.17 & 0.87 & 0.06 & 3.3 & 0.095 & 147 \\
\hline \multicolumn{9}{|l|}{ SBA-15 (wt\%) } \\
\hline 5 & $180 \pm 2$ & 0.011 & 0.180 & 0.93 & 0.22 & 4.3 & 0.13 & 127 \\
\hline 10 & $178 \pm 2$ & 0.026 & 0.250 & 1.10 & 0.27 & 4.1 & 0.08 & 150 \\
\hline 15 & $182 \pm 2$ & 0.003 & 0.069 & 0.84 & 0.10 & 4.6 & 0.07 & 165 \\
\hline 20 & $179 \pm 2$ & 0.005 & 0.099 & 1.00 & 0.15 & 4.8 & 0.21 & 100 \\
\hline \multicolumn{9}{|l|}{$\mathrm{HiSil}^{\mathrm{TM}}(\mathrm{wt} \%)$} \\
\hline 5 & $179 \pm 2$ & 0.044 & 0.333 & 1.20 & 0.21 & 3.5 & 0.06 & 172 \\
\hline 10 & $181 \pm 2$ & 0.006 & 0.014 & 0.85 & 0.04 & n.a. & 0.07 & 171 \\
\hline 15 & $183 \pm 2$ & 0.013 & 0.019 & 0.99 & 0.14 & 3.0 & 0.14 & 115 \\
\hline
\end{tabular}

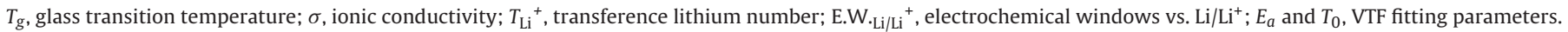

of the $-\mathrm{CH}_{2}-$ and $-\mathrm{CF}_{2}-$ groups, respectively [28]. The peaks of the HFP carbons are expected to fall at $\sim 92(-\mathrm{CFH}-), \sim 123\left(-\mathrm{CF}_{2}-\right)$ and $\sim 127 \mathrm{ppm}\left(-\mathrm{CF}_{3}\right)$ [29]. The two high-frequency features are masked by the very large peak due to the $\mathrm{CF}_{2}$ groups of the vinilidene chains, whereas the resonance at $\sim 92 \mathrm{ppm}$ is only barely observable above the baseline. Despite of the large quantity of ionic liquid absorbed in the membrane, the narrow features characteristic of the liquid state are non-observed in both the spectra, which confirms that our samples are gel electrolytes, where the polymer strands are swollen by the liquid phase. Nicotera et al. [30] reported the ${ }^{13} \mathrm{C}$ NMR solution spectrum of the ionic liquid $N$-methyl- $N$-propyl-pyrrolidinium bis(trifluoromethanesulfonyl)imide ( $\mathrm{PYR}_{13} \mathrm{TFSI}$ ) which is similar to that reported here, except for the presence of a $-\mathrm{CH}_{3}$ group instead of the $-\mathrm{OCH}_{3}$ one at the end of one side chain (see Scheme 1). Following Ref. [30], we can assign the large feature at $\sim 65 \mathrm{ppm}$ to the $-\mathrm{CH}_{2}$ groups bonded to the nitrogen. On the other hand, also the resonance of the ether methylene carbon $\left(-\mathrm{CH}_{2} \mathrm{O}-\right)$ of the side chain is expected to fall in this spectral region [31]. The remaining $-\mathrm{CH}_{2}$ - groups of the cation ring fall near $20 \mathrm{ppm}$, and give origin to a small feature well observed in the spectrum of the sample with filler (red plot). The methyl group of the short side chain falls around $47 \mathrm{ppm}$, and it is visible as a shoulder of the intense $-\mathrm{CH}_{2}$ - resonance of the polymer backbone. The resonance of ether methyl group $\left(-\mathrm{OCH}_{3}\right)$ should fall in the range $50-60 \mathrm{ppm}$ [31], but cannot be clearly observed in the spectra. Finally, the signal of the $-\mathrm{CF}_{3}$ groups lies in the same spectral region of the $-\mathrm{CF}_{2}-$ groups [30]. By comparing the two spectra of Fig. 3, we can conclude that the addition of the filler does not cause relevant changes to the NMR signature, so suggesting that the interactions among the filler and the polymer gel electrolyte are weak.

\subsubsection{Thermal properties, morphology and ionic conductivity}

Table 1 reports some physical and electrochemical parameters of the PVdF-HFP gel composite electrolytes. The glass transition temperature, $T_{g}$, the ionic conductivity, $\sigma$, the lithium transference number, $\mathrm{T}_{\mathrm{Li}}{ }^{+}$, the electrochemical stability, $E_{\mathrm{Li} / \mathrm{Li}}{ }^{+}$, and the ionic transport parameters are shown as a function of the nature and concentration of the filler.

The use of the two fillers does not affect the thermal properties of the membranes, even at the highest filler concentrations. Glass transition temperatures around $180 \mathrm{~K}$, similar to that one of the unfilled system, are measured for all the composite gels. Further, each sample is stable at least up to $300^{\circ} \mathrm{C}$, independently on the presence of silica, as detected by thermogravimetric analyses not shown here.

In contrast, the filler plays an important role in the transport properties of the membrane electrolytes. The table shows the conductivity values of the gels at three different temperatures, i.e. $-20,20$ and $60^{\circ} \mathrm{C}$. In both the composite systems two maxima are clearly detected, which are peaked at 10 and $5 \mathrm{wt} \%$ of SBA-15 and $\mathrm{HiSil}^{\mathrm{TM}}$, respectively. Room temperature conductivity exceed- ing $0.25 \mathrm{mS} \mathrm{cm}^{-1}$ is easily obtained, which is less than one order of magnitude lower than that of the ionic liquid electrolyte. The two maxima are well pronounced in the temperature range from $-20^{\circ} \mathrm{C}$ to room temperature, whereas at higher temperatures the differences are not so relevant. It is a well-known fact that the addition of an inert, or quasi-inert, filler to a conducting phase determines a maximum of the conductivity in the range 5-15 wt\%, depending on several parameters, such as the nature of filler and polymer, the membrane preparation, and the transport mechanism [12]. For higher concentrations, the filler has a dilution effect acting as a physical barrier to the ion migration. In the particular case of $\mathrm{Li}$ conducting polymer electrolytes, maxima at $10 \mathrm{wt} \%$ are commonly observed [14], mostly in the presence of mesoporous structures like SBA-15 [32]. With regards to $\mathrm{HiSil}^{\mathrm{TM}}$, maxima at $5 \mathrm{wt} \%$ were observed in our laboratory on polybenzimidazole-based proton conducting membranes [33].

These results are consistent with the morphology data. Fig. 4 shows the SEM images for the gel electrolytes containing 5 and $10 \mathrm{wt} \%$ of SBA-15 (parts b and d) and of HiSil ${ }^{\mathrm{TM}}$ (parts c and e), respectively. The image of the pure PVdF-HFP membrane is also reported as a comparison. In each case, the swollen structure of the polymers can be noted. However, in the samples containing $10 \mathrm{wt} \%$ of SBA-15 and $5 \mathrm{wt} \%$ of $\mathrm{HiSil}^{\mathrm{TM}}$, the polymer domains seem to be more interconnected with respect to the other compositions, in agreement with the maxima in conductivity reported in Table 1.

Fig. 5 shows the Arrhenius plots in the temperature range -25 to $60{ }^{\circ} \mathrm{C}$ for the SBA-15 (part a) and for the HiSil ${ }^{\mathrm{TM}}$ based gel electrolytes (part $b$ ). The behaviour of the conductivity is well described by the Vogel-Tammann-Fulcher (VTF) equation [12]

$\sigma(T)=A T^{-0.5} e^{B / T-T_{0}}$

where $A$ is the pre-exponential factor, $T_{0}$ is a reference temperature which usually falls in the range $20-50 \mathrm{~K}$ below the $T_{g}$, and $B$ is a pseudo-activation energy for the charge-carriers motion. The VTF Eq. (2) is a phenomenological way to interpret ion transport (or viscosity) data in amorphous polymer electrolytes above the glass transition [34]. In particular, VTF behaviours of viscosity and conductivity have been reported for ionic liquids [35]. Empirically, the VTF parameters can be obtained by fitting the conductivity data in terms of the linearized relationship [36]

$\log _{10}\left(\sigma T^{\frac{1}{2}}\right)=\log _{10} A-0.43 \frac{E_{a}}{k_{b}\left(T-T_{0}\right)}$

as shown in Fig. 6. Here, $E_{a}$ is the activation energy and $k_{b}$ is the Boltzmann constant. The values of the best-fitting parameters $E_{a}$ and $T_{0}$ for the unfilled and composite gel electrolytes are reported in Table 1 . Both the parameters are affected by the presence of the silica filler. The activation energies are generally near to the value calculated for the PYRA 1201 -based liquid electrolyte $\left(E_{a}=0.12 \mathrm{eV}\right)$ [6]. However, they show a non-linear behaviour vs. the fillers content, with minima at the compositions giving the highest con- 


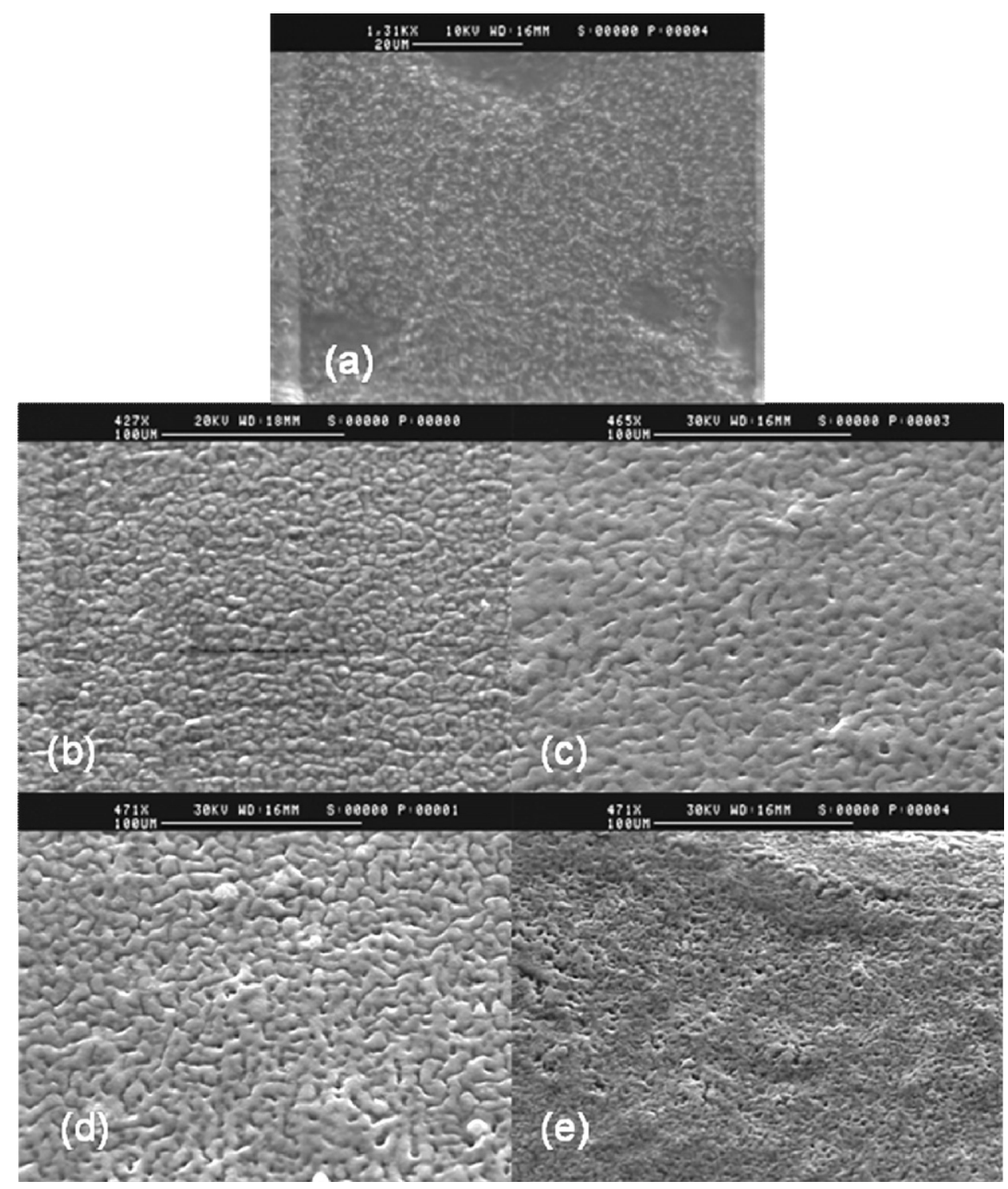

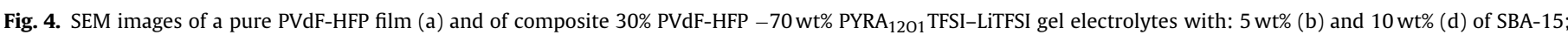
$5 \mathrm{wt} \%$ (c) and $10 \mathrm{wt} \%$ (e) of $\mathrm{HiSil}^{\mathrm{TM}}$.

ductivity values, and namely $10 \mathrm{wt} \%$ of SBA-15 $\left(E_{a}=0.08 \mathrm{eV}\right)$, and $5 \mathrm{wt} \%$ of and $\mathrm{HiSil}^{\mathrm{TM}}\left(E_{a}=0.06 \mathrm{eV}\right)$. At higher silica contents the activation energy increases, mostly in case of mesoporous $\mathrm{SiO}_{2}$, which is somehow expected if we consider the barrier effects against the ion motion which occur in the presence of large amounts of filler.

$T_{0}$ in the range $100-165 \mathrm{~K}$ have been determined for the SBAbased composites, in good agreement with the calorimetric glass transition temperatures obtained by DSC (see Table 1 ). Notably, $T_{0}$ values very near to the $T_{g}$ have been found for the electrolytes filled with low contents of $\mathrm{HiSil}^{\mathrm{TM}}$. This can be due to the presence of the -OH groups on the filler surface, which may stiffen the polymer structure by H-bonding, without affecting the ionic conductivity. The sample with $15 \mathrm{wt} \%$ of $\mathrm{HiSil}^{\mathrm{TM}}$ is anomalous, and we have no clear-cut explanation for this.

\subsubsection{Lithium transference number, $T_{L i}{ }^{+}$}

The lithium transference number, $\mathrm{T}_{\mathrm{Li}}{ }^{+}$, is a key factor in the optimization of electrolytes for lithium batteries. High $\mathrm{T}_{\mathrm{Li}}{ }^{+}$, in fact, guarantees high enough power density. Table 1 reports the transference numbers for the unfilled gel and the composites ones.
As typically observed in the case of ionic liquids and gel electrolytes, the $T_{\mathrm{Li}}{ }^{+}$of the membranes are not high. However, the addition of a filler remarkably increases $T_{\mathrm{Li}}{ }^{+}$of the membranes, and $T_{\mathrm{Li}}{ }^{+}$up to 0.27 were obtained in case of the samples with SBA-15. The positive effect of the filler on the lithium transport number was already noted in these systems $[17,19,32]$, and it was attributed to Lewis acid-base interactions between the surface acid sites of the filler and the lithium salt anion, which allow a higher fraction of $\mathrm{Li}^{+}$to be available for the conduction. $\mathrm{T}_{\mathrm{Li}}{ }^{+}$maxima are found for the samples showing the maxima of conductivity, namely those with $10 \mathrm{wt} \%$ of SBA- 15 and $5 \mathrm{wt} \%$ of $\mathrm{HiSil}^{\mathrm{TM}}$, similarly to what observed for other composite PVdF-based electrolytes [32].

\subsubsection{Electrochemical stability of the Li/electrolyte interface}

Fig. 7 shows the voltammetry linear sweeps for the unfilled PVdF electrolytes (solid line) and the composite films containing $10 \mathrm{wt} \%$ of SBA-15 (dotted line), and $5 \mathrm{wt} \%$ of $\mathrm{HiSil}^{\mathrm{TM}}$ (dash-dot line). Both the fillers improve the electrochemical stability of the gels, and the best performances are obtained with SBA-15. The good performances of the mesoporous filler in terms of interface stability 

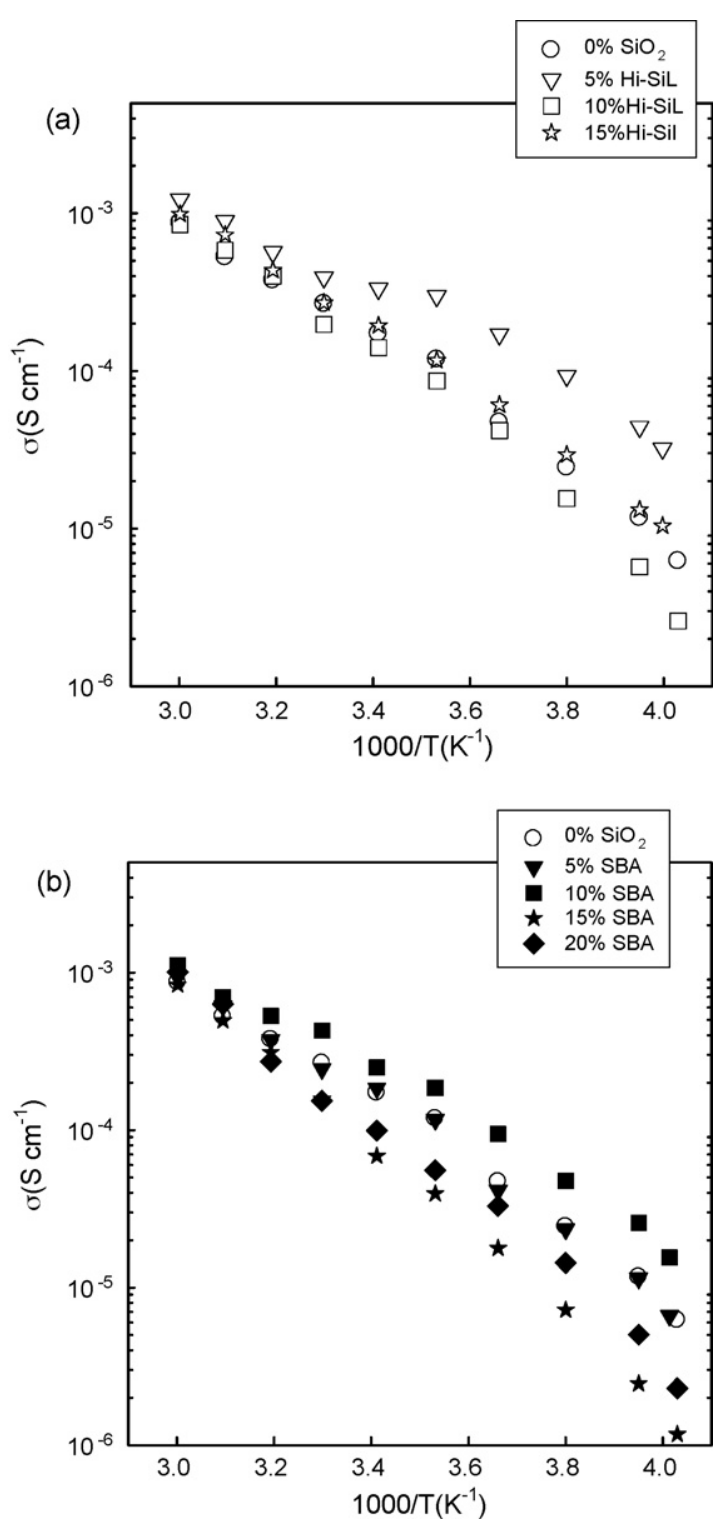

Fig. 5. (a) Conductivity Arrhenius plots of the unfilled gel electrolyte (open circles) and of the composite films with $5 \mathrm{wt} \%$ (open triangle), $10 \mathrm{wt} \%$ (open squares), and $15 \mathrm{wt} \%$ (open stars) of $\mathrm{HiSil}{ }^{\mathrm{TM}}$. (b) Conductivity Arrhenius plots of the unfilled gel electrolyte (open circle) and of the composite films with $5 \mathrm{wt} \%$ (filled triangle), $10 \mathrm{wt} \%$ (filled squares) and $15 \mathrm{wt} \%$ (filled stars), and $20 \mathrm{wt} \%$ (filled diamonds) of SBA-15.

are likely related to its hierarchical microstructure, which allows a more homogeneous particle distribution through the matrix with a consequent larger polymer/filler interface. This aspect is further confirmed by measurements of lithium interfacial resistance and battery tests.

Fig. 8 shows the behaviour with time of the interfacial resistance, $R_{i}$, for the polymer gel without filler (circles) and with $10 \mathrm{wt} \%$ of SBA-15 (squares) in a symmetrical Li/GPE/Li cell. The inset reports the impedance spectra at $t=7$ and $t=30$ days for both the membranes. As typically observed in these systems, in both cases the interfacial resistance increases immediately after the cell assembly, due to the formation of passivation layers on the lithium electrodes. However, in the case of the SBA-based membrane, $R_{i}$ quickly reaches a stability plateau around $150 \Omega \mathrm{cm}^{-2}$, whereas in the unfilled gel it continuously grows with time, reaching values which are about five times higher than those of the composite electrolyte.

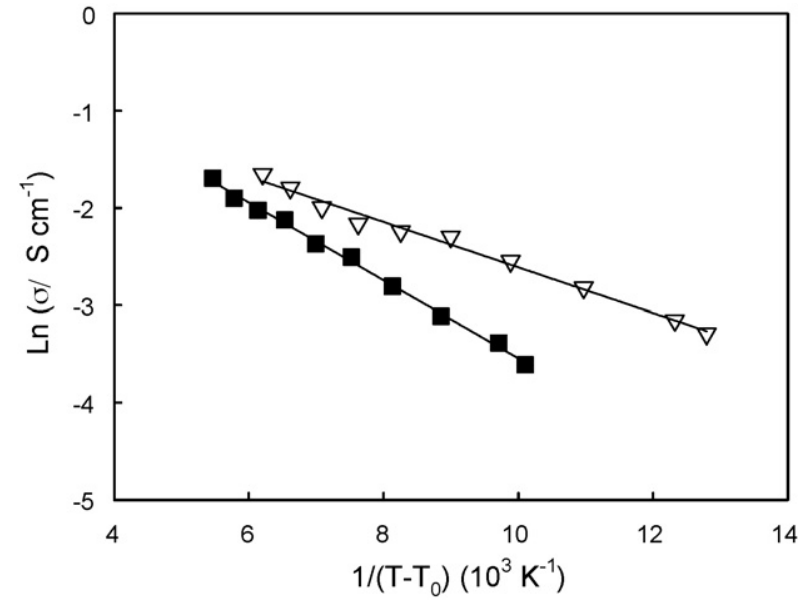

Fig. 6. Linear best-fits of the conductivity data of the composite gel electrolytes in terms of Eq. (3). Open triangles: $5 \mathrm{wt} \%$ of $\mathrm{HiSil}^{\mathrm{TM}}$, fit goodness $r^{2}=0.994$; filled squares: $10 \mathrm{wt} \%$ of SBA-15, fit goodness $r^{2}=0.998$. The best-fits were obtained by treating $T_{0}$ as a parameter.

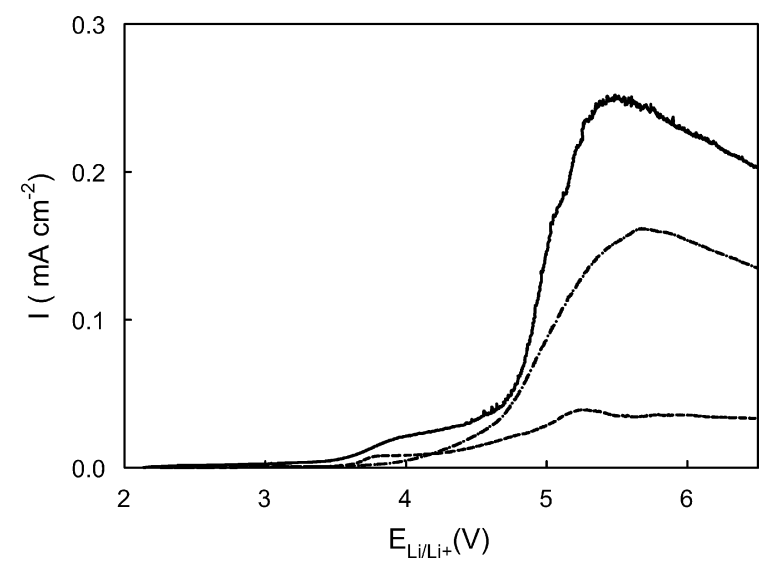

Fig. 7. Linear voltammetry plots vs. $\mathrm{Li} / \mathrm{Li}^{+}$of some gel electrolytes: unfilled membrane (solid line); 5 wt\% of $\mathrm{HiSil}^{\mathrm{TM}}$ (dash-dot line); $10 \mathrm{wt} \%$ of SBA-15 (dashed line) Scan rate: $5 \mathrm{mV} \mathrm{s}^{-1}$

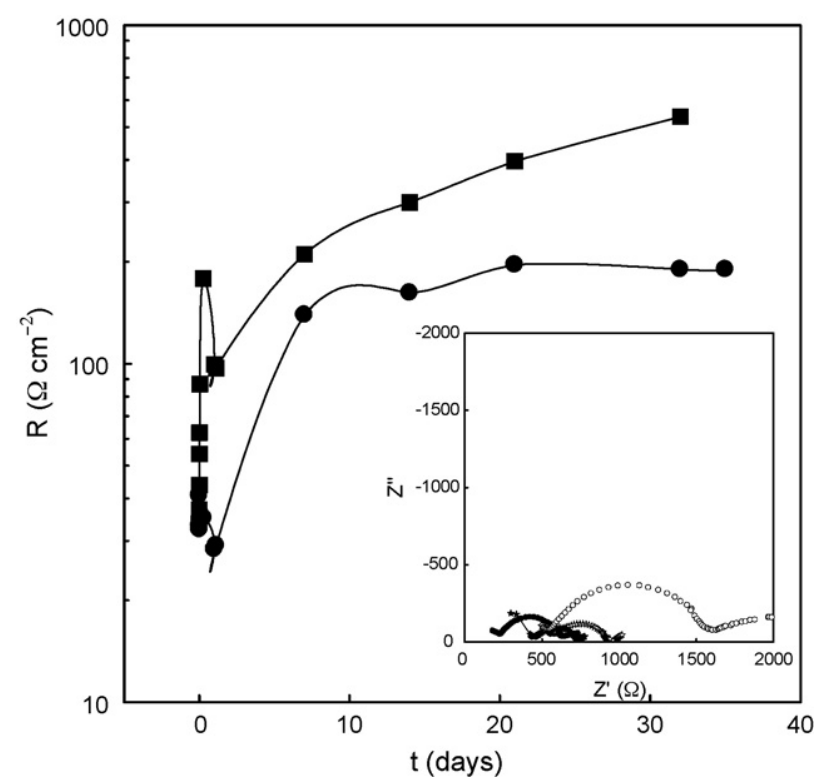

Fig. 8. Evolution of the interfacial resistance at room temperature in a $\mathrm{Li} / \mathrm{Li}^{+}$cell with a unfilled PVdF-HFP membrane (filled squares) and a composite gel electrolyte containing $10 \mathrm{wt} \%$ of SBA-15 (filled circles). The inset shows the impedance spectra of the unfilled gel (circles) and of the composite electrolyte (stars) after 7 days (open symbols) and 30 days (filled symbols). 


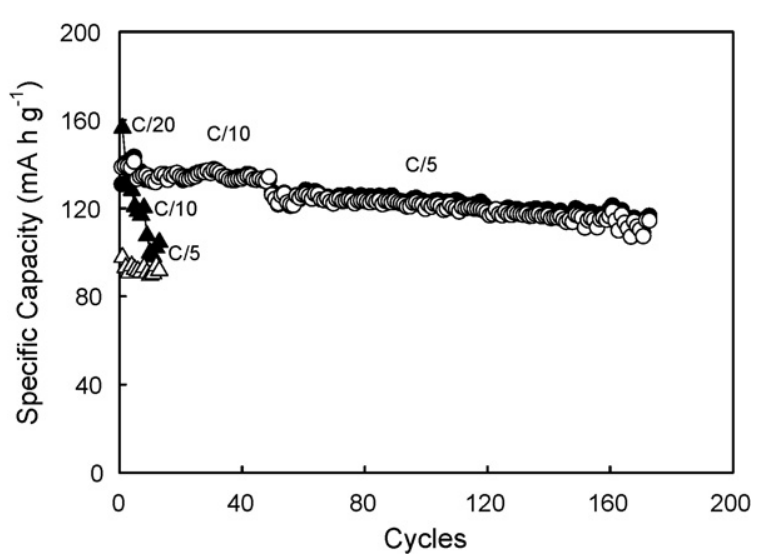

Fig. 9. Cycling behavior of $\mathrm{Li} / \mathrm{LiFePO}_{4}$ cells containing the ionic liquid electrolyte PYRA $_{1201}$ TFSI-LiTFSI $\left(m=0.41 \mathrm{~mol} \mathrm{~kg}^{-1}\right)$ (triangles) and of the composite gel electrolyte with $10 \mathrm{wt} \%$ of SBA-15 (circles). Open symbols: discharge capacity; filled symbols: charge capacity. $5 \mathrm{wt} \%$ of propylene carbonate was added to both the liquid and the gel electrolyte.

\subsection{Battery test on $\mathrm{Li} / \mathrm{GPE} / \mathrm{LiFePO}_{4}$ cells}

The battery performances of the composite gel electrolytes were studied at room temperature by assembling a $\mathrm{Li} / \mathrm{GPE} / \mathrm{LiFePO}_{4}$ cell. Two composite systems were initially selected for the tests: (i) the membrane containing $10 \mathrm{wt} \%$ of SBA-15, and (ii) the one with $5 \mathrm{wt} \%$ of $\mathrm{HiSil}^{\mathrm{TM}}$. The films showed very different behaviours of the specific capacity. At C/20 the observed capacities were quite similar, ranging around $150 \mathrm{mAh} \mathrm{g}^{-1}$. At faster charging rates the capacity decreased for both the gels, but more dramatically in the case of the GPE with HiSil ${ }^{\mathrm{TM}}$. In fact, from $\mathrm{C} / 10$ to $\mathrm{C} / 5$ the membrane filled with SBA-15 showed a capacity decrease from 100 to $50 \mathrm{mAh} \mathrm{g}^{-1}$, whereas the HiSil ${ }^{\mathrm{TM}}$-based one showed $C=50 \mathrm{mAh} \mathrm{g}^{-1}$ at $\mathrm{C} / 10$ and stopped to work at higher rates. Our attention was therefore focused on the $10 \mathrm{wt} \% \mathrm{SBA}-15$ composite membrane. In order to improve the electrolyte performances, $5 \mathrm{wt} \%$ of propylene carbonate (PC) was added both to the composite membrane and to the pure ionic liquid with the lithium salt. It was recently reported in the literature that the addition of small amounts of ethylene carbonate improves the electrochemical performances of PVdF-HFP systems gelled with ionic liquids without substantial alteration of the thermal and anodic stability of the electrolyte [10].

Fig. 9 shows the performances of the $\mathrm{Li} / \mathrm{GPE} / \mathrm{LiFePO}_{4}$ cell at three different $C$ rates $(C / 20, C / 10$ and $C / 5)$. The same test for the ionic liquid electrolyte is reported for the sake of the comparison. The composite gel shows promising properties in terms of capacity retention and reversibility. Upon continuous cycling the specific capacity of the composite gel changes from 139 to $124 \mathrm{mAh} \mathrm{g}^{-1}$ at the 174 th cycle. At the first cycle $C_{\text {discharge }}$ is about $85 \%$ of the nominal capacity $\left(170 \mathrm{mAh}^{-1}\right)$. The observed values are in fair agreement with the cycle behaviour and the rate performances of batteries $\mathrm{Li} / \mathrm{LiFePO}_{4}$ with polymer electrolytes gelled with ionic liquids [14,37]. During the overall cycling test the discharge efficiency, determined by the ratio between the discharge and charge capacities, is very close to $100 \%$ at each investigated $C$ rate. In particular the efficiency average value is 99\% (see Fig. 10). The liquid electrolyte shows worse cycling properties. More precisely, the capacity quickly decreases from $156 \mathrm{mAh}^{-1}$ at the first charge cycle ( $\sim 92 \%$ of the nominal capacity) to $89 \mathrm{mAh} \mathrm{g}^{-1}$ after only 13 cycles. In this case, the efficiency is not constant throughout the entire test, but it increases with the number of cycles and the average value is $89 \%$. Therefore the presence of the filled polymer leads to the stabilization with time of the electrochemical properties of the salt-ionic liquid solution.

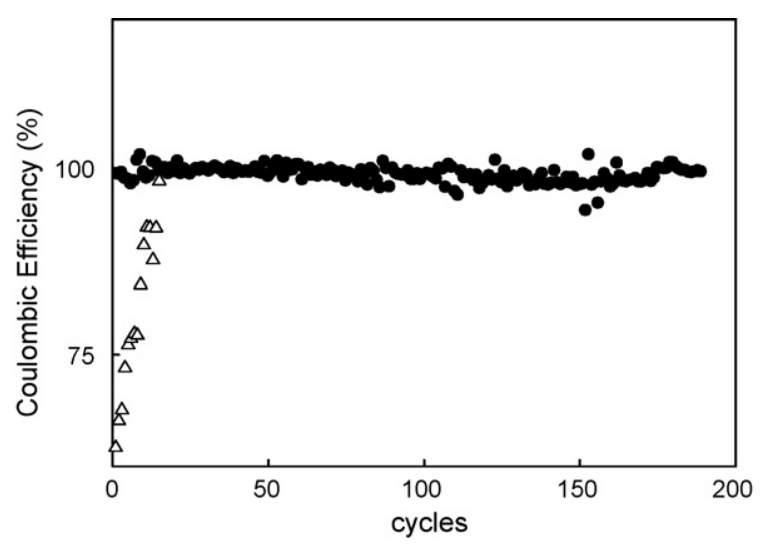

Fig. 10. Discharge efficiency of the $\mathrm{Li} / \mathrm{LiFePO}_{4}$ cells containing the ionic liquid electrolyte PYRA 1201 TFSI-LiTFSI $\left(m=0.41 \mathrm{~mol} \mathrm{~kg}^{-1}\right.$ ) (open triangles) and of the composite gel electrolyte with $10 \mathrm{wt} \%$ of SBA-15 (filled circles).

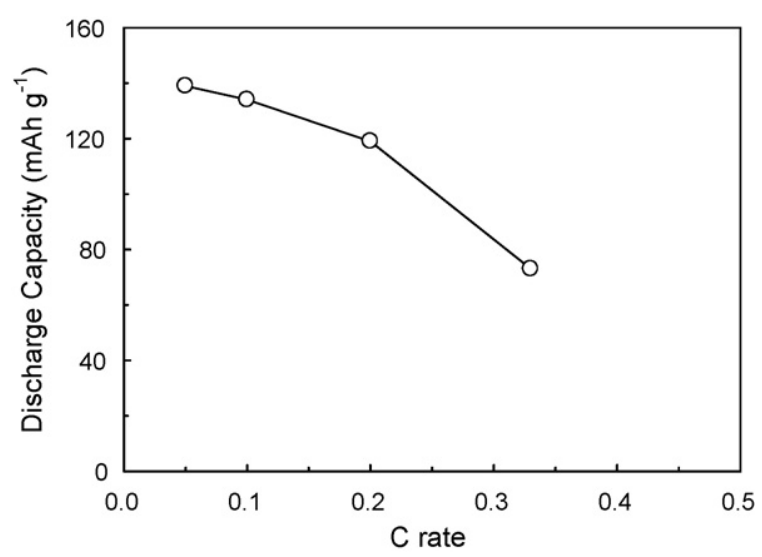

Fig. 11. Discharge capacity of the $\mathrm{Li} / \mathrm{LiFePO}_{4}$ cell with the composite gel electrolyte filled by $10 \mathrm{wt} \%$ of SBA- $15 \mathrm{vs}$. the discharge rate.

Finally, Fig. 11 shows the behaviour of the discharge capacity of the composite gel electrolyte at different $C$ rates. In agreement with the literature (see for example Ref. [37]), the discharge capacity of the cathode remarkably depends on the discharge rate. This was explained in terms of low electric conductivity and/or low lithium diffusivity in the composite cathode [38]. In the case of the composite membrane the drop in capacity at $C$ rates higher than 0.3 is about $50 \%$.

\section{Conclusions}

Composite electrolytes based on PVdF-HFP gelled with a $0.41 \mathrm{~mol} \mathrm{~kg}^{-1}$ solution of LiTFSI in PYRA 1201 TFSI were prepared and characterized. Two different types of fillers were used, a mesoporous silica (SBA-15) and a commercial nano-size one (HiSil ${ }^{\mathrm{TM}}$ T700). Both the composite gel electrolytes displayed comparable thermal stability and ionic conductivity. Conductivity maxima higher than $0.25 \mathrm{mS} \mathrm{cm}^{-1}$ are observed in both the systems, and more precisely at $5 \mathrm{wt} \%$ of $\mathrm{HiSil}^{\mathrm{TM}}$ and $10 \mathrm{wt} \%$ of SBA- 15 .

However, the gel electrolytes filled with mesoporous silica showed better electrochemical and stability properties, likely because of a larger polymer/filler interphase, and of the lower number of $-\mathrm{OH}$ groups on the filler surface. In particular, lithium transference numbers up to 0.27 and wider electrochemical windows exceeding $4 \mathrm{~V}$ were observed in the membranes with a SBA compositional range between 5 and $20 \mathrm{wt} \%$.

The solid-state $\mathrm{Li} / \mathrm{LiFePO}_{4}$ battery based on GPEs filled with the mesoporous silica showed good capacity and cycling properties up 
to medium $C$ rates $(C / 5)$ throughout 180 cycles. Discharge efficiency very close to unit was observed, independently on the explored $C$ rate.

\section{Acknowledgement}

We gratefully acknowledge funding from CARIPLO Foundation (Project 2006.0688/10.8485 "Nuove membrane elettrolitiche nanocomposite a base di liquidi ionici”).

\section{References}

[1] M. Armand, J.-M. Tarascon, Nature 451 (2008) 652.

[2] G.B. Appetecchi, S. Scaccia, C. Tizzoni, F. Alessandrini, S. Passerini, J. Electrochem. Soc. 153 (2006) A1685.

[3] D.R. MacFarlane, P. Meakin, J. Sun, N. Amini, M. Forsyth, J. Phys. Chem. B 103 (1999) 4164.

[4] D.R. MacFarlane, M. Forsyth, P.C. Howlett, J.M. Pringle, J. Sun, G. Annat, W. Neil, E.I. Izgorodina, Acc. Chem. Res. 40 (2007) 1165.

[5] D.R. MacFarlane, J. Huang, M. Forsyth, Nature 402 (1999) 792.

[6] S. Ferrari, E. Quartarone, P. Mustarelli, A. Magistris, S. Protti, S. Lazzaroni, M. Fagnoni, A. Albini, J. Power Sources 194 (2009) 45.

[7] J. Fuller, A.C. Breda, R.T. Carlin, J. Electrochem. Soc. 144 (1997) L67.

[8] S.-H. Yeon, K.-S. Kim, S. Choi, J.-H. Cha, H. Lee, J. Phys. Chem. B 109(2005) 17298.

[9] D. Bansal, F. Cassel, F. Croce, M. Hendrickson, E. Plichta, M. Salomon, J. Phys. Chem. B 109 (2005) 4492.

[10] H. Ye, J. Huang, J.J. Xu, A. Khalfan, S.G. Greenbaum, J. Electrochem. Soc. 154 (2007) A1048.

[11] R.C. Agrawal, G.P. Pandey, J. Phys. D 41 (2008) 223001.

[12] E. Quartarone, P. Mustarelli, A. Magistris, Solid State Ionics 110 (1998) 1.

[13] V. Aravindan, P. Vickraman, T. Prem Kumar, J. Non Cryst. Solids 354 (2008) 3451

[14] H. Xie, Z. Tang, Z. Li, Y. He, Y. Liu, H. Wang, J. Solid State Electrochem. 12 (2008) 1497.
[15] M. Watchler, D. Ostrovskii, P. Jacobsson, B. Scrosati, Electrochim. Acta 50 (2004) 357.

[16] G. Vijayakumar, S.N. Karthick, A.R. Sathiya Priya, S. Ramalingam, A. Subramania, J. Solid State Electrochem. 12 (2008) 1135

[17] M. Stolarska, L. Niedzicki, R. Borkowska, A. Zalewska, W. Wieczorek, Electrochim. Acta 53 (2007) 1512.

[18] M. Walkowiak, A. Zalewska, T. Jesionowski, M. Pokora, J. Power Sources 173 (2007) 721.

[19] J. Xi, X. Tan, Chem. Phys. Lett. 400 (2004) 68.

[20] C.-G. Wu, M.-I. Lu, C.-C. Tsai, H.-J. Chuang, J. Power Sources 159 (2006) 295.

[21] Y.-X. Jiang, Z.-F. Chen, Q.-C. Zhuang, J.-M. Xu, Q.-F. Dong, L. Huang, S.-G. Sun, J. Power Sources 160 (2006) 1320.

[22] X.L. Wang, Q. Cai, L.-Z Fan, T. Hua, Y.-H. Lin, C.-W. Nan, Electrochim. Acta 53 (2008) 8001.

[23] C. Gerbaldi, G. Meligrana, S. Bodoardo, A. Tuel, N. Penazzi, J. Power Sources 174 (2007) 501.

[24] G. Meligrana, C. Gerbaldi, A. Tuel, S. Bodoardo, N. Penazzi, J. Power Sources 160 (2006) 516.

[25] P.G. Bruce, J. Evans, C.A. Vincent, Solid State Ionics 28-30 (1988) 918.

[26] J. Evans, C.A. Vincent, P.G. Bruce, Polymer 28 (1987) 2324.

[27] K.M. Johansson, J. Adebahr, P.C. Howlett, M. Forsyth, D.R. Macfarlane, Aust. J. Chem. 60 (2007) 57.

[28] C. Hucher, F. Beaume, R.-P. Eustache, P. Tekely, Macromolecules 38(2005) 1789.

[29] Z. Ge, X. Zhang, J. Dai, W. Li, Y. Luo, Eur. Polym. J. 45 (2009) 530.

[30] I. Nicotera, C. Oliviero, W.A. Henderson, G.B. Appetecchi, S. Passerini, J. Phys. Chem. B 109 (2005) 22814.

[31] See, for example, Bruker Almanac, NMR Tables, 2005

[32] J. Xi, X. Qiu, W. Zhu, X. Tang, Micropor. Mesopor. Mater. 88 (2006) 1

[33] P. Mustarelli, A. Carollo, S. Grandi, E. Quartarone, C. Tomasi, S. Leonardi, A. Magistris, Fuel Cells 7 (2007) 441.

[34] Bamford, A. Reiche, G. Dlubek, F. Alloin, J.-Y. Sanchez, M.A. Alam, J. Chem. Phys 118 (2003) 9420.

[35] A. Noda, K. Hayamizu, M. Watanabe, J. Phys. Chem. B 105 (2001) 4603.

[36] B. Wang, S.Q. Li, S.J. Wang, Phys. Rev. B 56 (1997) 11503.

[37] J.-H. Shin, W.A. Henderson, S. Scaccia, P.P. Prosini, S. Passerini, J. Power Sources 156 (2006) 560

[38] J. Shim, K.A. Striebel, J. Power Sources 119-121 (2003) 955. 